\title{
Seca e Determinismo: a Gênese do Discurso do Semi-árido Nordestino
}

\author{
Rafael Winter Ribeiro \\ Mestrando do Programa de Pós-Graduação em Geografia/UFRJ
}

\begin{abstract}
The recent material published in the press concerning Northeast region of Brazil (Nordeste) shows a direct association between the region's low levels of social and economic development and its semi-arid nature. This perspective reveals a deterministic treatment of the matter. This article investigates both the origins and the avatars of such a deterministic view based on the works of the members of Instituto do Ceará, created in 1887. The analysis of this material has shown that, in the late nineteenth and early twentieth centuries, a group of authors emphasized the climate as a conditioning factor to the region's progress. During the same period, another set of articles describes the previous periods of drought ("secas") accentuating their tragic aspects. Yet they do not establish any direct relationship between the climate and the region's poverty or wealth. In the first half of this century these views were overwhelmed by another one, that identifies the environment and the aridness as the causes of the region's underdevelopment. Since then, this last one has become the hegemonic
\end{abstract}

\section{Introdução}

O Nordeste do Brasil é talvez a região do país sobre a qual mais se escreveu até hoje. Ao longo da história, a região tem sido tratada como uma questão a ser resolvida - a questão Nordeste -, ganhando o estigma de "região problema”, já que guarda em seu conjunto os piores índices de desenvolvimento econômico e social do país. Ao lado disso, a região possui características naturais singulares no Brasil, tendo em boa parte de seu território a ocorrência do clima semi-árido. Característica natural deste clima, a seca compõe o principal elemento do imaginário regional veiculado e difundi- 
do nacionalmente através dos meios de comunicação e da bibliografia acadêmica. Nestes trabalhos, além da ligação forte entre a sociedade e a natureza, na maior parte deles, a natureza é trabalhada discursivamente como a causa principal do atraso regional. A seca, bem como a escassez de água no sertão, são apontadas, na maioria dos discursos, como as grandes responsáveis pela miséria que atinge a região.

Uma simples comparação com outras regiões semi-áridas do globo revelam o falseamento dessa questão. O clima árido da Califórnia ou de Israel não lançou suas populações em um estado de miséria. A existência de populações miseráveis ou ricas em diferentes regiões semi-áridas do globo aponta para os diferentes padrões de ocupação ao longo da história como a principal razão dos desníveis regionais existentes no semi-árido (CASTRO, 1994, 1996). Essa associação entre clima e pobreza revela um tratamento determinista da questão que contamina, mesmo que inconscientemente, boa parte da produção intelectual e cultural da e sobre a região.

Dessa forma, do ponto de vista do discurso regional, podemos falar na existência de um determinismo geográfico nordestino, que acompanha até hoje o imaginário da região, apesar de teorias deterministas há muito serem rechaçadas por grande parte dos geógrafos.

Alguns autores, em especial CARVALHO (1988) e CASTRO (1992), mostram como a permanência desse discurso está ligada às estratégias da elite regional conservadora para conseguir maior participação na divisão das verbas federais. Tal fato evidencia a importância da interpretação do discurso, na medida em que este é um forte instrumento de legitimação da atuação dos diferentes grupos sobre o espaço.

O objetivo deste trabalho é investigar algumas das origens do discurso atual sobre a seca; identificar os responsáveis por sua construção e as matrizes do pensamento geográfico às quais estes estão ligados; e, mais especificamente, pretende-se verificar em que contexto o determinismo geográfico foi introduzido no discurso sobre a seca, sabendo-se que, mesmo após seu suposto abandono pela academia, continua no imaginário da região justificando práticas sociais de uma elite responsável pela sua reprodução. A base empírica do trabalho está apoiada em artigos de jornais publicados entre 1992 e 1994 no centro-sul e no nordeste sobre a seca e na produção da Revista do Instituto do Ceará publicada a partir de 1887. Nos primeiros trata-se de 
destacar o determinismo subsumido nas referências ao fenômeno da seca hoje, enquanto no segundo busca-se identificar os seus fundamentos.

\section{Em Busca de um Referencial Teórico e Metodológico.}

\subsection{Ciência e Determinismo.}

A palavra determinismo aparece pela primeira vez em alemão por volta de 1830, significando a relação absoluta e necessária entre fenômenos e suas causas. Suas virtudes para o desenvolvimento das ciências foram fundamentais, uma vez que ele se opunha ao fatalismo, à idéia de vontades superiores ou de forças ocultas e a toda subjetividade na explicação científica. Na realidade, a questão da causalidade objetiva, racional, com base na experimentação rigorosa foi fundamental para a elaboração do discurso científico e para a elaboração de teorias e leis, problemas fundadores da ciência moderna e necessários aos avanços do conhecimento científico. Para Gellner, o determinismo é :

o termo que designa uma doutrina, segundo a qual todos os objetos ou acontecimentos, ou todos os objetos ou acontecimentos de uma mesma espécie (por exemplo, os que fazem parte de alguma disciplina científica) são determinados, i. e. devem ser como são e como serão, em virtude de certas leis ou forças que façam com que necessariamente assim sejam. Na realidade, determinismo é o nome de toda uma classe de teorias que têm em comum a característica anteriormente citada. O termo torna-se, então, nome de uma doutrina específica quando o tipo de determinismo é indicado, implícita ou explicitamente. A especificação pode indicar a classe das coisas que são determinadas, o tipo de coisa que as determina, ou ambos (...). (GELLNER, 1986: 340)

O termo determinismo, indica portanto, de modo simplificado, uma relação de causa e efeito. Nesse sentido, todos os acontecimentos seriam regidos por leis implacáveis, externas a eles e sempre que determinadas circunstâncias se repetirem, se repetirão também os resultados. A fórmula determinista é, portanto, uma fórmula de previsão do futuro, para o qual, conhecendo todas as variáveis do presente será possível determinar sua resultante. 
Laplace concebe um sistema que se tornou famoso e é uma das melhores definições para o determinismo universal.

Uma inteligência que, em um dado instante conheceria todas as forças pelas quais a Natureza é animada e a situação respectiva dos seres que a compõem, se além disso ela fosse bastante vasta para submeter esses dados à análise, abrangeria dentro de uma só fórmula os movimentos dos maiores corpos do Universo e os do átomo mais leve: nada seria incerto para ela e tanto o futuro quanto o passado estariam presentes a seus olhos. Todos os esforços do espírito humano dentro da busca da verdade tenderiam a reaproximá-lo incessantemente da inteligência que acabamos de conceber. (LAPLACE, apud MOLES, 1995: 28)

A ciência torna-se assim, um meio para a descoberta das leis pelas quais o universo é regido e deveria aproximar-se cada vez mais dessa inteligência superior. Segundo essa abordagem, qualquer outro conhecimento que não buscasse a obtenção dessas leis não deveria ser considerado ciência. Ser determinista no sentido de Laplace, é ter por previsível, nos pequenos detalhes, de uma maneira unívoca o futuro inteiro do Universo e de cada partícula que ele engloba (Pomian, 1990: 13). Neste esquema também não há autonomia dos elementos na medida em que estes são determinados pela conjugação dos elementos do passado. Ao longo do tempo outras variantes foram desenvolvidas, no entanto, o fundamento determinista continua na idéia de previsibilidade e de causalidade ${ }^{1}$.

A necessidade de conhecimento das determinações para a função legiferante da ciência moderna, fez do determinismo, mais do que um princípio experimental e metodológico, uma doutrina que confere a uma ordem de fatos o papel preponderante, ou exclusivo, do encadeamento das causas.

Não cabe aqui estender a discussão da evolução do problema do determinismo científico frente aos novos paradigmas que se delineiam neste final de século para as ciências. Deve ser retida no entanto, a importância da busca de causalidades objetivas

\footnotetext{
${ }^{1}$ Não cabe aqui uma discussão detalhada acerca das nuances e matizes dentro da matriz determinista, tal como a encontrada em Pomian (1990); o que é pretendido aqui é apenas analisar o cerne da questão determinista.
} 
na construção da Geografia Acadêmica no século passado e a elaboração de um discurso científico-geográfico, em consonância com os rigores da academia.

\subsection{Determinismo Geográfico}

Na Geografia, tendo em vista a perspectiva de maior aproximação com as ciências naturais e o rigor de suas formulações, o determinismo da natureza, que buscava explicar os fatos geográficos a partir de suas causas naturais, foi por longo tempo dominante. Este determinismo natural foi oficialmente repudiado pela Geografia contemporânea, no entanto, continua a contaminar, na prática, o imaginário social e encontra-se subsumido em numerosos escritos geográficos.

Para Pinchemel, “o determinismo geográfico é a manifestação indiscutível da influência de um ou muitos fatos de ordem natural, solo, relevo, clima, ..., sobre os grupamentos humanos e suas atividades, [e] essa influência possui um valor de causa, explicativa do fato humano considerado" (PINCHEMEL, 1957: 213). Essa relação Homem / Meio constituiu um dos primeiros paradigmas da Geografia, e para este autor, é ela que faz da Geografia uma ciência integrativa, sem a qual seria apenas uma ciência social. Entretanto, essa abordagem existiu mesmo antes da institucionalização da própria disciplina. Os primórdios remontam à Antigüidade Clássica, onde já se indagava se as diferenças climáticas, sob as quais nascem os homens, interferem em suas diferenças de espírito, debate encontrado, por exemplo, em Hipócrates e no livro VII da Política de Aristóteles.

Claval delimita três raízes principais do determinismo ambiental na Geografia: cosmologia antiga e medicina hipocrática, teleologia herderiana e evolucionismo darwiniano (Claval, 1985: 110). A primeira idéia de influência do ambiente sobre o homem é originária da medicina grega de tradição hipocrática que passa a procurar as causas das doenças do homem no ambiente. Bastante influenciada também pela cosmologia antiga, a idéia de que o cosmos pesa sobre a natureza de cada ser e sobre o seu destino é desenvolvida concomitantemente. Tal concepção é retomada em parte pelo naturalismo do século XVIII, com Montesquieu e sua famosa teoria dos climas. A relação Homem/Clima e, especialmente, a relação com a temperatura é pensada e elaborada discursivamente na busca de causalidades para as diferenças encontradas 
em sociedades de diferentes partes do mundo. Retomando a tradição médica/hipocrática, Montesquieu afirma que:

Tem-se, assim, mais vigor nos climas frios (...). Esta força maior deve produzir muitos efeitos. Por exemplo: Mais confiança em si mesmo, isto é, mais coragem, mais conhecimento de sua superioridade, isto é, menos desejo de vingança; mais certeza de sua segurança, isto é, mais franqueza, menos suspeitas, menos política, menos malícia (...). Os povos das regiões quentes são tímidos, como os anciãos; os das regiões frias são corajosos como os jovens.(...) Ter-se-á, nas regiões frias, pouca sensibilidade para os prazeres; ele será maior nas regiões temperadas; nas regiões quentes será exagerada (...) (Monstesquieu, 1997: 277-279).

Um segundo tipo de determinismo é desenvolvido na segunda metade do século XVII e apoia-se na filosofia herderiana. Ao contrário do primeiro tipo, faz uma leitura muito próxima ao não-racionalismo e segundo seus princípios, o mundo teria sido moldado por Deus. O plano divino poderia ser lido no mundo e o destino do homem estaria marcado no ambiente em que este vive. Como mostra Gomes (1996: 183) esse tipo de determinismo, em lugar de estabelecer leis procura fazer uma leitura dos signos da natureza, fazendo com isso, uma substituição da explicação pela interpretação. Dessa forma, o determinismo estaria aqui, ligado a um sistema de causas bastante distinto do rigor científico. A temática proposta por Herder conheceu um grande sucesso na Alemanha do fim do século XVIII e começo do século XIX. Na Geografia, Ritter e Reclus se encarregaram de introduzi-la.

O terceiro tipo, foi o que encontrou maior posteridade e é aquele que está apoiado nas teorias evolucionistas de Darwin. O Darwinismo deu ao ambiente um papel determinante na evolução: não é o meio que modela os seres, mas é ele que os seleciona. Já que o homem faz parte do mundo, sua evolução também deve se explicar pelos mesmos motivos.

A Geografia não ficou alheia à grande repercussão que o evolucionismo obteve nos mais diversos campos da ciência na segunda metade do século XIX. É neste mesmo período que o determinismo geográfico atinge o seu auge, estando intimamente ligado ao processo de institucionalização da Geografia como disciplina universitária, já que para esta ser considerada um saber científico no ambiente positivista do 
final do século, era necessário que fosse capaz de prever o mundo, de estabelecer leis:

No bojo do processo que buscava uma compreensão efetivamente científica da relação homem/meio, surge o determinismo geográfico. Atendia às expectativas acerca da cientificidade da Geografia, estabelecendo como nas demais disciplinas relações de causalidade e envolvendo raciocínios dedutivos através de mecanismo de determinação. (GOMES, 1987: 33).

Foi a escola alemã a primeira a surgir e que melhor desenvolveu essa linha, com Friedrich Ratzel à sua frente. Foi por meio do evolucionismo que Ratzel deu à Geografia uma perspectiva rigorosa, objetiva e geral, permitindo-lhe que ascendesse à categoria das ciências positivas modernas. Bastante influenciado pelas teorias evolucionistas, via o homem como o resultado final de uma evolução, como o produto do meio, moldado por este. Nesse ponto, a idéia de causa e efeito imediatamente determináveis, que prevalecera até então é substituída por uma determinação produzida ao longo de um processo de evolução e de diferenciação (GOMES, 1996: 185-186). Não se deve, entretanto, associar o determinismo geográfico do final do século XIX apenas à Alemanha e especialmente a Ratzel, que foi um dos mais importantes sem dúvida, mas é verdade que esta proposta encontrou simpatizantes de diversas nacionalidades (GOMES, 1996).

No Brasil, uma das principais vias de entrada do determinismo geográfico foi através do debate em torno do conceito de raça. O debate sobre as vantagens e desvantagens da ação do clima tropical e da estrutura do relevo sobre o povo é algo inerente ao pensamento geográfico brasileiro do final do século XIX e início do século XX (MACHADO, 1995).

Principalmente a partir da segunda metade deste século, a imensa maioria dos geógrafos passa a, oficialmente, repudiar o determinismo geográfico puro como explicação científica. Entretanto, nesse período, apesar de rechaçado pela academia, o determinismo continua a contaminar o imaginário social, estando presente até mesmo em vários manuais de ensino e é encontrado subsumido também, em alguns textos acadêmicos de geógrafos que não se consideram deterministas, como podemos observar claramente no imaginário sobre a região Nordeste do Brasil hoje. 


\subsection{Geografia e Discurso}

A Geografia pouco tem se preocupado com a questão da linguagem e do discurso. A maioria dos trabalhos geográficos que abordam essa questão estão preocupados com a cientificidade do discurso da própria Geografia ${ }^{2}$ ou constituem análises sobre a forma com a qual determinado geógrafo escreve ${ }^{3}$. Até agora, a maior parte dos geógrafos tem negligenciado o fato de que um discurso reflete o grupo social responsável pala sua produção e que esse grupo está inserido em um tempo e um espaço determinado. O discurso é capaz de revelar muito das estratégias de atuação sobre o espaço destes grupos, quando muito os geógrafos fazem referência a tal fato mas não o consideram como essencial em sua análise. Este trabalho procura trazer para a Geografia algumas questões da análise do discurso, das quais os geógrafos até agora têm se mantido afastados. Procura-se buscar algumas referências nas teorias de análise de conteúdo e do discurso, para a coleta e tratamento dos dados empíricos, mas sem com isso importar um modelo pronto e fechado de análise.

No debate relativo às técnicas de análise de discurso, há duas posições opostas: aqueles que vêem a análise de discurso como um conjunto de técnicas dentro da análise de conteúdo e os defensores da análise de discurso como um campo independente. Além disso, entre os analistas de discurso há um embate entre a Escola Americana e Escola Francesa de Análise do discurso.

Para Bardin (1994) a análise de conteúdo representa um papel de "técnicas de ruptura” face à intuição aleatória e fácil, constituindo atualmente um conjunto de instrumentos metodológicos que se aplicam a discursos extremamente diversificados e onde a análise do discurso, representa apenas uma técnica a mais dentro deste conjunto. O fator comum dentro da multiplicidade de técnicas que existem para a autora, está baseado em uma hermenêutica controlada, baseada na dedução: a inferência.

Enquanto esforço de interpretação, a análise de conteúdo oscila entre dois pólos: o rigor da objetividade e a fecundidade da subjetividade. Essas duas abordagens

2 - Um exemplo desse tipo de trabalho é encontrado na obra do professor Paul Claval (1984) em que o autor faz na verdade um estudo sobre a história das matrizes do pensamento geográfico. $\mathrm{O}$ trabalho de V. Berdoulay (1988) também é outro exemplo desse tipo.

3 - Exemplo do segundo tipo é encontrado no trabalho de Simansky (1976), onde o autor aborda o estilo discursivo adotado na obra do geógrafo D. W. Meining. 
têm dividido pesquisadores até hoje. Enquanto na análise quantitativa o que é relevante na informação é a freqüência com que surgem certas características de conteúdo, na análise qualitativa é a presença ou ausência de determinadas características num discurso que é tomado em consideração.

Ainda segundo esta autora, existem três fases distintas que devem ser seguidas em qualquer variância na análise de conteúdo. A primeira delas é a descrição, enumeração das características do texto, resumida após tratamento. A segunda é a inferência, baseada em deduções lógicas permitindo a passagem clara e controlada à terceira fase que é a interpretação. Durante a fase da inferência podem ser respondidas duas questões: o que é que conduziu a um determinado enunciado e/ou quais as conseqüências que um determinado enunciado vai provocar. A primeira diz respeito às causas e antecedentes da mensagem enquanto que a segunda refere-se aos seus possíveis efeitos.

A análise do discurso surge na década de 1960 em um momento de domínio do estruturalismo tanto na lingüística como nas ciências sociais. Um dos responsáveis pelo seu desenvolvimento e difusão, Michel Pêcheux, desenvolveu uma série de métodos de tratamento dos textos o qual chamou de Análise Automática do Discurso. Para ele, a análise do discurso deveria substituir a análise de conteúdo, na medida em que essa segunda teria provado ser incapaz de dar objetividade aos seus resultados (PÊCHEUX, 1993). Dessa forma, sua preocupação básica estava ligada à objetividade, almejada através dos programas de computadores que desenvolveu para análise dos textos ${ }^{4}$.

Michel Pêcheux construiu seu corpus teórico através de uma análise das teorias lingüísticas existentes. Para Pêcheux o deslocamento conceitual realizado por Saussure provocou uma mudança de objeto da lingüística, permitindo que algumas questões importantes fossem postas de lado por esta disciplina. Com Saussure a língua passa a ser compreendida como um sistema tendo a função de exprimir sentido, o objeto da ciência lingǘstica passa a ser então o de descrever o seu funcionamento. O texto não mais pode ser objeto pertinente para a lingüística na medida em que este não possui um funcionamento, o que possui é a língua. A análise do discurso surge então, nesse brecha deixada pela lingüística.

4 - Para maiores informações sobre o funcionamento dos métodos e do programa desenvolvidos por Pêcheux ver: HAROCHE, C. \& PÊCHEUX, M. (1972). 
Uma crítica que muitos fazem da obra de Pêcheux está ligada ao fato de que o autor teria avançado muito na teoria, tendo conseguido criar um grande corpus teórico mas suas técnicas apresentariam muitos problemas de ordem prática, problemas esses que são reconhecidos pelo próprio autor (PÊCHEUX e FUCHS, 1993).

Preocupada em redefinir alguns conceitos da chamada "Escola Francesa de Análise do Discurso”, Maingueneau (1993) afirma que esta não pode ser mais definida apenas como o estudo lingüístico das condições de produção de um enunciado, como era até então. É necessário que se faça uma melhor precisão dos critérios para melhor analisar a experiência que realiza. Ao contrário do que faz a escola americana, dominada por correntes interacionistas e etnometodológicas, que toma como objeto essencial de estudo a conversação ordinária, a escola francesa relaciona-se com textos com as seguintes características:

1. Produzidos no quadro de instituições que restringem fortemente a enunciação;

2. Nos quais se cristalizam conflitos históricos, sociais, etc.;

3. Nos textos que delimitam um espaço próprio no exterior de um interdiscurso limitado.

Pierre Bourdieu (1983) critica todos os modelos tradicionais de análise ligados excessivamente à lingüística, entre os quais, o modelo criado por Michel Pêcheux. Bourdieu, em seu trabalho, está preocupado principalmente com os mecanismos de circulação dos discursos, onde o grau de legitimidade do locutor definiria, em grande parte, o grau de aceitabilidade do discurso. Para ele, é um erro procurar a "força locutória” no próprio discurso, já que o que “fala” nunca é o discurso, mas toda a pessoa social (1983: 167). Para realizar uma análise verdadeira é necessário identificar “quem fala”(o produtor), “para quem”(o leitor), “de onde”(a instituição a que pertence e o veículo) e “como” (a forma discursiva) estabelecendo seus graus de legitimidade.

Uma ciência do discurso almejada por Bourdieu deveria estabelecer as leis que determinam quem pode falar, a quem e como, já que todo o discurso supõe um emissor legítimo dirigindo-se a um destinatário legítimo, reconhecido e reconhecedor.

Uma questão importante que surge daí, é o fato de que o discurso não é autoexplicativo, existindo portanto, a necessidade de conhecer as condições de constituição do grupo no qual o discurso funciona para poder explicá-lo. Entretanto, é necessário observar não somente as relações de força simbólicas que se estabelecem no grupo em questão, mas também as próprias leis de produção do grupo que fazem com que 
certas categorias estejam ausentes. Essas “condições ocultas”, como chama Bourdieu, seriam determinantes para compreender o que pode e o que não pode ser dito num dado grupo. Dessa forma, um dado importante é que o discurso deve sempre uma parte muito importante de seu valor ao valor daquele que o domina. A estrutura da relação de produção lingüística depende da relação simbólica entre dois locutores, isto é, da importância de seu capital de autoridade.

É de fundamental importância para a Geografia e para o nosso trabalho assumir que a atividade discursiva, como qualquer outra atividade, não se desenvolve fora do espaço e do tempo. O discurso é reflexo dos grupos que são responsáveis por sua elaboração, recepção e reprodução e, dessa forma, reflete o tempo e espaço em que atuam. Assim, investigar o discurso, as idéias, símbolos e mensagens que ele veicula é uma das opções metodológicas para entender como determinados grupos organizam seus territórios. Mais do que isso, por esse ponto de vista, o discurso funciona como um elemento legitimador de uma organização do espaço, na medida em que, sobretudo em sociedades ditas democráticas, dependerá da capacidade de seu locutor de se fazer acreditar, e da vontade de ouvir de quem recebe a mensagem que serão tomadas atitudes que poderão influenciar sobre a organização do território.

\section{O Determinismo geográfico nordestino}

\subsection{Determinismo no discurso da seca}

A ligação entre a natureza da região Nordeste, classificada por muitos como hostil, e seu atraso econômico feito por deduções lógicas simples é muito comum e seu tratamento, em vários textos, revela um viés determinista.

O texto do Deputado Osvaldo Coelho (1985), é um exemplo claro e didático desse viés. Em discurso pronunciado na Câmara dos Deputados em 21 de novembro de 1984, o Deputado procura defender recursos para a irrigação no Nordeste. Em sua fala a seca é tratada como o grande problema da região e causa de suas mazelas:

A escassez de água no Nordeste já fez vítimas incontáveis, desagregou famílias, semeou miséria e sofrimento. Condenou a região a uma posição de inferioridade no cenário nacional (...) (COELHO, 1985: 07). 
Fica evidente no trecho citado que a inferioridade do Nordeste é causada pela seca. A escassez de água, uma característica do clima semi-árido na região, é apontada como fator do seu atraso. Este é um exemplo do que chamamos de Determinismo Geográfico Nordestino, pois ao qualificar a seca como a principal causa da pobreza nordestina, através de um mecanismo de dedução, fica claro uma relação causal entre a característica física da região e o seu grau de desenvolvimento. Ao longo do discurso, a seca é qualificada com a utilização de uma quantidade muito grande de adjetivos que dão a idéia de inexorabilidade do clima.

A terrível e prolongada seca nordestina, destruidora de vidas, causa de sofrimentos incontáveis e de grandes prejuízos, aparentemente cessou. As chuvas voltaram depois de cinco anos de estiagem, colorindo a paisagem e fazendo renascer no nosso povo a tímida esperança por melhores dias. (COELHO, 1985: 6).

É possível notar no texto oposição entre a ocorrência da seca, trazendo consigo todos os seus problemas, e os períodos chuvosos, onde é possível à população retomar a esperança que, tímida, duraria apenas até a próxima estiagem. Assim, existe uma contraposição entre seca, ligada ao atraso, e chuva, ligada ao progresso.

No discurso, a seca é também posta como um problema nacional, e não apenas regional, quando o autor afirma que: “foram anos penosos, realidade medonha que violentou e ultrajou, mais uma vez, a dignidade, a honra e a decência nacionais” (COELHO, 1985: 6). Com a utilização desse recurso, o autor traz a discussão para uma escala nacional. No discurso, apesar de a seca não atingir todo o país, ao afetar uma parte considerável de sua população, exibindo com contornos trágicos a sua miséria, deveria ferir os brios da nação. Dessa forma, a questão torna-se um problema nacional e não regional. Tal argumento fornece maior legitimidade ao discurso frente aos seus receptores (a Câmara Nacional).

Através de um encadeamento lógico o autor conclui que o problema do progresso passa pela questão da erradicação da fome e da miséria e reside na questão da existência ou não de água.

A fome e a desnutrição representam os mais drásticos obstáculos ao progresso e ao desenvolvimento. Fome e desnutrição se combatem com uma agricultura forte, que receba cuidado prioritário e soluções urgentes. E a matéria-prima da agricultura é a água (COELHO, 1985: 6). 
O esquema apresentado no quadro I representa o encadeamento lógicodiscursivo do texto, onde a falta d’água, teria como conseqüências finais a fome, miséria e o atraso econômico.

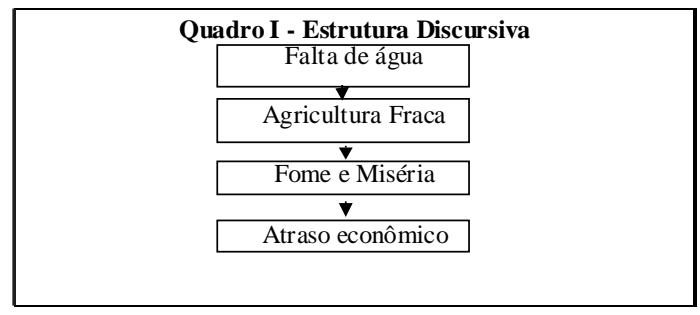

Dessa forma, o discurso aponta para a constatação de que onde não existe água não pode haver desenvolvimento. A solução do problema do atraso regional estaria então em investimentos para tornar a água disponível. Esse tipo de solução encontra uma longa tradição na região, tal como apontada por Carvalho (1988), que a define como "solução hidráulica”.

\section{2 A seca na imprensa}

Realizando uma análise de artigos sobre a seca publicados em jornais e revistas é possível identificar que seu caráter trágico é, na imensa maioria das vezes, destacado e ressaltado. Para este trabalho, foi realizada uma análise temática de artigos de jornais publicados entre 1992 e 19945 , onde foram decodificadas as estruturas individuais de cada texto, agrupando-os segundo essas estruturas ${ }^{6}$. O objetivo principal é identificar como o tema "seca” vem sendo trabalhado na imprensa nacional na atualidade, além de identificar padrões de abordagens segundo a procedência do autor.

Foram analisados um total de 57 artigos publicados em importantes jornais do Centro-Sul ${ }^{7}$, além do jornal O Povo, de Fortaleza, nos quais o critério de seleção dos artigos foi o de conter algum relato sobre o tema "seca”.

Os artigos foram classificados primeiro segundo a abordagem dada ao tema e logo após suas estruturas discursivas foram decodificadas e agrupadas. Para observar

\footnotetext{
${ }^{5}$ Período dentro do qual, houve a ocorrência de mais um evento de estiagem no Nordeste.

${ }^{6}$ Um trabalho semelhante foi realizado por Castro (1992) para os discursos dos Deputados na Câmara Federal.

${ }^{7}$ A análise foi realizada em artigos publicados no Jornal do Brasil e O Globo, do Rio de Janeiro; e O Estado de São Paulo e Folha de São Paulo, de São Paulo.
} 
a existência ou não de diferença no caráter do discurso segundo diferentes regiões, os artigos também foram classificados segundo a procedência do relatante em "representante do Centro-Sul” ou em "representante do Nordeste”.

No Quadro II os textos são decompostos e agrupados segundo seu encadea-

Quadro II Estrutura dos artigos sobre a seca veiculados em jornais de 1992 a 1994

\begin{tabular}{|c|c|c|c|c|c|}
\hline \multicolumn{6}{|c|}{ Encadeamento discursivo dos Textos } \\
\hline $1^{\mathrm{a}}$ & $2^{a}$ & $3^{\mathrm{a}}$ & $4^{\mathrm{a}}$ & $5^{\mathrm{a}}$ & Ocorrências \\
\hline Seca & Pobreza e fome & Saque e tensão social & & & 03 \\
\hline Seca & Pobreza e fome & $\begin{array}{l}\text { Necessidade de } \\
\text { medidas } \\
\text { emergênciais }\end{array}$ & & & 08 \\
\hline Seca & Pobreza e fome & $\begin{array}{l}\text { Necessidade de } \\
\text { medidas } \\
\text { emergênciais }\end{array}$ & $\begin{array}{l}\text { Clientelismo e uso } \\
\text { político }\end{array}$ & & 20 \\
\hline Seca & Pobreza e fome & $\begin{array}{l}\text { Necessidade de } \\
\text { medidas } \\
\text { emergênciais }\end{array}$ & $\begin{array}{l}\text { Clientelismo e uso } \\
\text { político }\end{array}$ & $\begin{array}{l}\text { Necessidade de } \\
\text { medidas de } \\
\text { caráter } \\
\text { permanente }\end{array}$ & 06 \\
\hline Seca & $\begin{array}{l}\text { Medidas de caráter } \\
\text { provisório }\end{array}$ & Perpetuação da seca & $\begin{array}{l}\text { Necessidade de } \\
\text { medidas de caráter } \\
\text { permanente }\end{array}$ & & 06 \\
\hline Seca & $\begin{array}{l}\text { Falta de sustentação } \\
\text { do município sem } \\
\text { apoio federal }\end{array}$ & Exodo rural & & & 02 \\
\hline Seca & $\begin{array}{l}\text { Necessidade de } \\
\text { obras federais de } \\
\text { emergência }\end{array}$ & $\begin{array}{l}\text { Obras realizadas sem } \\
\text { critério e } \\
\text { abandonadas }\end{array}$ & $\begin{array}{l}\text { Piora da situação da } \\
\text { população }\end{array}$ & & 02 \\
\hline Seca & $\begin{array}{l}\text { Necessidade de } \\
\text { mais verbas e } \\
\text { melhoria dos } \\
\text { programas }\end{array}$ & & & & 02 \\
\hline $\begin{array}{l}\text { Seca e } \\
\text { ineficiência } \\
\text { da ação do } \\
\text { governo }\end{array}$ & $\begin{array}{l}\text { Pobreza, humilhação } \\
\text { e uso político }\end{array}$ & & & & 03 \\
\hline $\begin{array}{l}\text { Seca e } \\
\text { desemprego } \\
\text { causado } \\
\text { pela } \\
\text { recessão }\end{array}$ & Miséria e fome & Saques & $\begin{array}{l}\text { Liberação de } \\
\text { recursos } \\
\text { emergênciais }\end{array}$ & & 02 \\
\hline Chuva & $\begin{array}{l}\text { Desativação das } \\
\text { frentes de trabalho }\end{array}$ & Miséria e fome & & & 03 \\
\hline
\end{tabular}

Fonte: Artigos de Jornais. 
mento lógico-discursivo. É possível identificar que de um total de 57 artigos, 37 fazem uma ligação imediata entre a seca e a pobreza e fome, e só então ligam estes aos demais problemas. Dessa forma, a seca é, em primeiro lugar, causa de pobreza e fome, a partir da qual viriam os demais problemas.

No quadro III os mesmos textos são agrupados segundo as formas de abordagem do tema seca e à origem dos locutores ${ }^{8}$, em representante do Centro-Sul e representante do Nordeste. É necessário lembrar que os textos poderiam ser classificados em mais de uma classe se abordassem mais de um tema contabilizado. Os dados evidenciam uma diferença do conteúdo do discurso entre os representantes das duas regiões. É possível notar que os representantes do Centro-Sul adotam uma postura muito maior de crítica, enquanto que os do Nordeste estão mais preocupados em demonstrar os estragos feitos e solicitar mais recursos.

\section{Quadro III Temas de discursos ligados à seca feitos por representantes do Nor- deste e do Centro-Sul de 1992 a 1994}

\begin{tabular}{|l|l|l|}
\hline & Centro-Sul & Nordeste \\
\hline Crítica à indústria da seca & 14 & 5 \\
\hline Crítica ao Programa de Cestas Básicas & 4 & 2 \\
\hline $\begin{array}{l}\text { Crítica às medidas de caráter provisório e } \\
\text { pedido de medidas permanentes }\end{array}$ & 4 & 4 \\
\hline Denúncia de conflitos pelo uso da água & 0 & 2 \\
\hline Mostra os estragos da seca & 2 & 3 \\
\hline $\begin{array}{l}\text { Estado de emergência e liberação de } \\
\text { recursos }\end{array}$ & 2 & 8 \\
\hline Falta de ajuda do Governo Federal & 1 & 4 \\
\hline Necessidade de obras & 3 & 4 \\
\hline Nega a existência da indústria da seca & 0 & 3 \\
\hline Crítica à desativação de frentes de trabalho & 1 & 3 \\
\hline
\end{tabular}

Fonte: artigos de jornais.

\footnotetext{
${ }^{8}$ A origem do autor foi definida a partir de informações no próprio texto que indicassem para tal. Na ausência desta, a origem do veículo de publicação foi o critério adotado.
} 
O principal alvo de críticas do Centro-Sul é a indústria da seca, criticada em 14 artigos, enquanto que há apenas 5 artigos de nordestinos com críticas a essa mesma indústria, que tem a sua existência até mesmo negada em 3 textos nordestinos. Nas críticas ao Programa de Cestas Básicas do Governo Federal, os representantes do Centro-Sul também possuem maioria: são 4, contra 2 do Nordeste.

Os representantes do Nordeste se destacam nos temas ligados à demonstração do caráter trágico da seca e no pedido de auxílios. Nos artigos que demonstram os estragos feitos pela seca, 3 são de nordestinos, enquanto 2 são do Centro-Sul. Nos artigos que relatam o estado de emergência e pedem recursos para o Nordeste, 8 são do Nordeste e apenas 2 são do Centro-Sul do país. Nas críticas à desativação das frentes de trabalhos, também são 3 do Nordeste, contra apenas 1 do Centro-Sul. Tal estratégia permitiu dar visibilidade ao fato de que o discurso sobre a seca varia, segundo os interesses dos grupos responsáveis por sua produção, como pode ser visualizado no quadro IV.

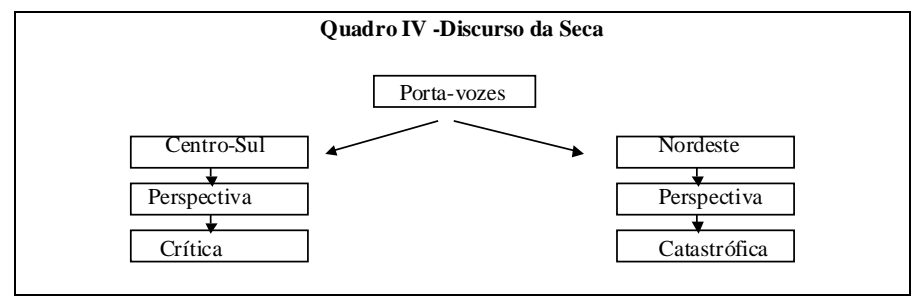

Hoje alguns autores, e em especial CASTRO (1992), têm demonstrado que a permanência desse discurso trágico na região está ligada a uma estratégia da elite política local para conseguir mais verbas do Governo Federal. A necessidade de dar à região uma “compensação” por seus azares climáticos e a impossibilidade de um auto-desenvolvimento em função da natureza hostil é o pano de fundo dessa estratégia.

A detenção por parte dessa elite política tradicional de um amplo acesso aos meios de comunicação faz com que essa idéia seja plenamente difundida, contaminando o imaginário social, e refletindo-se na produção acadêmica e jornalística sobre a região. Essa permanência desse discurso determinista também se dá pela facilidade de desenvolvimento e de assimilação de discursos baseados em deduções simples, como afirma Gomes: “(...) atribuir o papel de causa a certas circunstâncias e explicar os fenômenos como suas conseqüências diretas supõe uma lógica de base muito simples. (...) As raízes da 
reflexão determinista são de certa maneira inconscientes e inerentes à linguagem e ao pensamento.” (GOMES, 1996, p.175).

Pretendemos demonstrar a diante, com base na produção do Instituto do Ceará, como esse discurso, apoiado em uma visão trágica do Nordeste e com um conteúdo determinista em relação ao clima, teve seu início no final do século XIX.

\section{A Gênese do discurso da seca.}

\subsection{O Instituto Histórico e Geográfico Brasileiro e os Institutos Regionais.}

Na primeira metade do século XIX, com a implantação do Estado Nacional Brasileiro desvinculado politicamente de Portugal, cabe à intelectualidade brasileira a tarefa de forjar um perfil nacional capaz de garantir uma identidade singular à nova nação, no qual é dado um lugar especial à História e à Geografia. A Historiografia do Brasil no século XIX está preocupada com o projeto de traçar a gênese da nacionalidade brasileira, enquanto a Geografia, complementando esse projeto, se preocupa em retirar o véu que cobre o imenso território, quase todo desconhecido, sobre o qual emerge a nação.

Como mostra Guimarães (1988), a fundação do Instituto Histórico e Geográfico Brasileiro em 1838, no Rio de Janeiro, vem apontar para a materialização desse projeto. Baseado nos ideais iluministas, a produção do Instituto é feita pelas elites e para as elites, visando produzir uma homogeneização da visão do Brasil no interior destas. Contando em seus quadros com a elite intelectual do Império e inclusive com o apoio e participação do Imperador, o Instituto logo se transforma no locus a partir de onde se pensa o Brasil, contribuindo para uma progressiva difusão e homogeneização do projeto nacional no seio de suas elites (GUIMARÃES, 1988: 14).

As idéias e ideologias desenvolvidas através de um instrumental próprio à Geografia e Historiografia da época, contando com todo apoio oficial, vão aos poucos se impondo no imaginário nacional. Daí a importância das correntes filosóficas adotadas por essas disciplinas na constituição desse imaginário. Muitas delas, como é o caso do determinismo geográfico aqui em foco, estão presentes ainda hoje no senso comum sobre o país.

O projeto do Instituto previa a formação de entidades semelhantes nas províncias, diretamente subordinadas aos princípios formulados na capital do Império, onde deveriam ser concentrados a soma de conhecimentos acumulados sobre o Brasil. Esses institutos, dando prosseguimento ao projeto de construção de uma identidade nacional, deveriam também se preocupar com a definição de 
uma identidade provincial, justificando uma subdivisão regional do país, mas que, de forma alguma, deveria se sobrepor à identidade nacional.

A exaltação romântica dos símbolos e heróis da pátria, comum ao IHGB, também é uma constante nos institutos regionais, que contam também, com uma exaltação do local. Preocupados com as tradições, esses institutos passam a ter o conservadorismo como uma de suas marcas principais.

Os Institutos provinciais, segundo os planos do IHGB, funcionariam como instituições que contariam com a participação dos principais membros das elites locais e estariam responsabilizados pela coleta de informações nas províncias para o Instituto no Rio de Janeiro.

A forma adotada para a divulgação dos trabalhos realizados por seus membros era principalmente a publicação de revistas que, dependendo da instituição, poderia ter uma periodicidade mensal, trimestral ou semestral. Além de registrar as atividades da instituição através de seus relatórios, divulgar cerimônias e atos comemorativos diversos, parte considerável das revistas, sobretudo nos primeiros anos, era dirigida à publicação de fontes primárias como forma de resgatá-las. Entretanto, a publicação de artigos inéditos, biografias e resenhas de obras também estava presente.

\subsection{O Instituto do Ceará e as secas.}

A fundação do Instituto do Ceará ocorre em 1887. Com uma produção considerável, a sua revista é uma das que possui a melhor periodicidade. Entretanto é necessário notar que a circulação dessas revistas era bastante restrita. Uma análise desse material se faz então, mais necessária pela importância de seus membros, já que estes atuavam como difusores de idéias, ou para utilizar um termo desenvolvido por Pierre Bourdieu (1996), como porta-vozes, alguns dos quais exerciam grande importância dentro da elite cearense e mesmo brasileira9 .

\footnotetext{
${ }^{9} \mathrm{O}$ quadro dos sócios fundadores do Instituto era composto por doze pessoas provenientes da elite cearense, são eles: Paulino Nogueira Borges da Fonseca, Guilherme Studart, Joakim de Oliveira Catunda, João Augusto da Frota, João Batista Perdigão de Oliveira, Antônio Augusto de Vasconselos, Antonio Bezerra de Menezes, Júlio César da Fonseca Filho, Juvenal Galeano da Costa e Silva, José Sombra, Virgílio Brígido e Virgílio Augusto de Moraes.
} 
O Primeiro presidente do Instituto foi Paulino Nogueria que ocupou o cargo até 1908, ano de sua morte. Filho de família ilustre, formou-se na Faculdade de Direito de Recife. Membro do Partido Conservador, foi eleito Deputado em 1872 (ANDRADE, 1968). Paulino Noguera foi o principal responsável pelos sete primeiros tomos da Revista, onde sempre exerceu uma preocupação com a publicação de fontes primárias.

Em 1908, com a sua morte, Paulino Nogueira é sucedido por Thomaz Pompeu de Souza Brasil, que preside o Instituto também até a sua morte em 1929. Thomaz Pompeu, conhecido também como Thomaz Pompeu Filho, era membro de uma das famílias mais ilustres do Ceará. Era o segundo filho do Senador Pompeu, figura conhecida no Império e que produziu vários textos de cunho geográfico, inclusive um compêndio de Geografia adotado pelo Colégio Pedro II, no Rio de Janeiro. Thomaz Pompeu de certa forma dá uma continuidade ao trabalho de seu pai. Como membro e, mais tarde presidente, do Instituto do Ceará, Thomaz Pompeu se preocupou em rescrever e atualizar a obra deixada pelo Senador Pompeu.

Um outro membro da família Pompeu Brasil que se destacou na produção intelectual do Instituto sobre o Ceará, foi Thomaz Pompeu Brasil Sobrinho, neto do Senador Pompeu e sobrinho de Thomaz Pompeu Filho. Ingressou no Instituto do Ceará em 1928, aos 47 anos, e dez anos mais tarde foi eleito Presidente do Instituto, cargo que exerceu de 1938 a 1867, até a sua morte. Formado pela Escola de Minas de Ouro Preto, ingressou na administração pública, onde aos poucos foi sedo promovido até que conseguiu o cargo de Engenheiro Chefe do Primeiro Distrito da Inspetoria Federal de Obras Contra as Secas, do qual mais tarde foi Presidente. Publicou na imprensa vários artigos sobre geo-economia, cultura, secas, reflorestamento e ensino popular da agricultura. Via a Geografia como um prolongamento da História tendo sido bastante influenciado pela obra de F. Ratzel.

Pelo fato de a província, e logo após estado, do Ceará ter praticamente todo o seu território atingido periodicamente pelas secas, esta passa a ser uma constante nos trabalhos dos membros do Instituto. Na verdade o Instituto do Ceará é o IHG que mais se preocupa com essa questão, constituindo uma das primeiras instituições a se preocupar e a produzir trabalhos sobre o assunto.

No momento em que é fundado o IC - Instituto de Ceará - (1877) a questão principal do pensamento geográfico brasileiro é o estabelecimento do potencial e dos limites da natureza física, social e política do país diante das idéias de progresso (MACHADO, 1995: 310). O fato de que a elite cearense, se defrontava com uma região que possuía uma natureza ambiental diferente do restante do país, o semi-árido, fez 
com que boa parte de seus integrantes tomasse também uma posição diferenciada de seus colegas do sul junto à questão do progresso.

Foram analisados um total de 27 artigos sobre a seca, desde o primeiro número, publicado em 1887, até o mais recente (1993). Entretanto, os artigos contam com uma distribuição temporal bastante irregular, apresentada no quadroV.

Quadro V Distribuição periódica dos artigos analisados na Revista do Instituto do Ceará

\begin{tabular}{|l|c|c|c|c|c|c|c|c|c|}
\hline Período & $\begin{array}{c}1887-- \\
1896\end{array}$ & $\begin{array}{c}1897-- \\
1906\end{array}$ & $\begin{array}{c}1907-- \\
1916\end{array}$ & $\begin{array}{c}1917-- \\
1926\end{array}$ & $\begin{array}{c}1927-- \\
1936\end{array}$ & $\begin{array}{c}1937-- \\
1946\end{array}$ & $\begin{array}{c}1947-- \\
1956\end{array}$ & $\begin{array}{c}1957-- \\
1993\end{array}$ & Total \\
\hline Ocorrência & 06 & 03 & 05 & 03 & - & 04 & 02 & 04 & 27 \\
\hline
\end{tabular}

Dentro do período analisado, a partir da década de 1960 há uma quase extinção dos trabalhos ligados à temática da seca. Tal fato é explicado pela alteração do padrão editorial e a mudanças nos critérios da escolha dos sócios do Instituto, que passa a dar prioridade aos trabalhos ligados à História e ao resgate de fontes primárias. Isso é comprovado pela quase inexistência de geógrafos nos quadros do Instituto a partir de então $0^{10}$.

O trabalho sobre o material encontrado na Revista do Instituto do Ceará doravante RIC - foi dividido em três fases: a seleção do material, o tratamento e a análise propriamente dita. Para realizar uma primeira seleção dos artigos foi feita uma leitura por títulos, a partir da qual foram elaboradas fichas tipo bibliográficas (ECO, 1993) para todos aqueles textos ligados à Geografia da região. O passo seguinte foi realizar uma leitura atenta desses artigos onde eram selecionados aqueles nos quais a palavra seca aparecia; o que permitiu que ao final desse processo o universo de análise estivesse reduzido a 27 artigos.

A segunda fase, correspondente ao tratamento das informações, teve seu início com a elaboração de fichas tipo resumo, com uma pequena síntese do texto e fichas tipo citação, onde eram destacados trechos dos artigos (ECO, 1993). O procedimento utilizado para a seleção dos trechos constituiu em destacar dos textos as frases que continham a palavra chave principal "seca" e as palavras chave secundárias, "atraso / progresso", "desenvolvimento / subdesenvolvimento"; "riqueza / pobreza”, eleitaspreviamente, tal como indicadas no quadro VI.

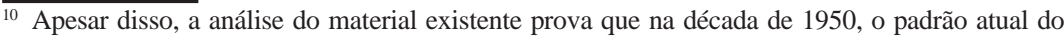
discurso da seca já era praticamente hegemônico nos trabalhos do Instituto, comprovando que a utilização desse material não é incoerente com os objetivos desse trabalho.
} 


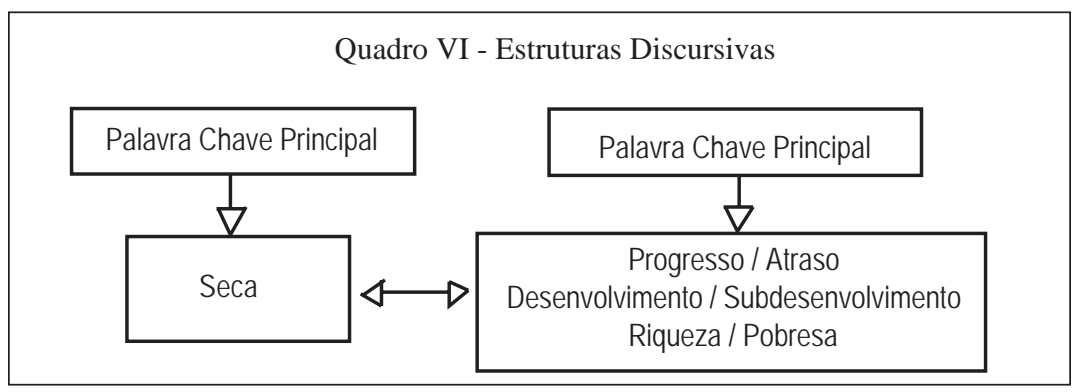

Juntamente com esses termos foram destacadas as frases imediatamente anteriores e imediatamente posteriores (eventualmente foram selecionados trechos maiores, para que não houvesse uma perda de sentido da frase principal).

A terceira fase, correspondente à análise, foi realizada a partir do agrupamento dos textos segundo o tratamento dado pelos autores à palavra chave principal "seca” e sua ligação com as palavras chave secundárias. Tal procedimento, permitiu identificar a existência de três eixos temáticos principais, com características internas homogêneas, que surgem ao longo do período analisado. O primeiro grupo de textos faz uma relação positiva entre o clima e o progresso da região, o qual chamaremos de "Clima e Progresso”. O segundo grupo possui como característica principal a descrição do clima e das secas e, a princípio, não faz uma relação com o condicionamento ao progresso ou ao atraso da região. Nesse grupo, a seca é sempre descrita com um caráter trágico, daí chamarmos de “Adjetivação Trágica”. O terceiro é aquele que se popularizou e que faz uma ligação entre o clima da região e seu atraso econômico, tal relação às vezes aparece apenas implicitamente, mas muitas outras é claramente delineada ao longo dos textos chamado, portanto, de “Clima e Atraso”. Por fim, procuramos explicar as condições que levaram ao surgimento e ao desaparecimento dos dois primeiros grupos, e ao estabelecimento de uma hegemonia do terceiro grupo de textos, a partir da segunda década deste século.

\section{Clima e progresso}

Como já foi dito, a fundação do Instituto do Ceará em 1887, ocorreu sob um ambiente romântico de exaltação da então província, de seus símbolos, heróis e natureza, desenvolvido ao longo do século XIX, onde havia a preocupação de estabelecimento de uma identidade cearense.

Esse ambiente propiciou a construção de um discurso característico do final do século XIX, onde mesmo as dificuldades do meio-ambiente nordestino são vistas de forma bastante positiva e guardando em si condições excepcionais 
para o desenvolvimento de uma sociedade. O clima condicionaria o progresso, facilitaria o trabalho e a procriação, gerando uma boa raça. A seca, quando citada, é apontada como mera adversidade temporária que nada impediria o desenvolvimento da região, já que as condições excepcionais do meio físico, incentivariam no homem um espírito de trabalho e de desenvolvimento das capacidades intelectuais, suplantando qualquer adversidade temporária. Era comum também a utilização da alta taxa de natalidade verificada na região como uma evidência da salubridade do clima para as pessoas a ele submetidas.

É fácil identificar o determinismo nesse discurso, porém com conteúdo social inverso àquele que foi vulgarizado mais tarde. A relação determinista aqui delineada apresenta uma relação de causa e efeito direta entre o meio-físico e o progresso.

Nesse grupo se encontram os trabalhos de Thomaz Pompeu de Souza Brasil, especialmente no seu artigo sobre a população do Ceará publicado em 1890 e influenciado por Henry Buckle (1823-1862), historiador e sociólogo inglês. Em seu livro lançado em 1857, Introduction to the history of civilization in England, Buckle afirmava que o progresso da civilização européia marcava-se pela influência cada vez menor do mundo natural, e na Europa em geral e na Inglaterra em particular, as forças mentais acabariam por sobrepujar as condições físicas. No entanto, negava tal fato para os demais continentes, nomeadamente para o Brasil, país que estaria acima de qualquer outro no que se refere a abundância de vida natural e onde a grandiosidade da natureza não deixaria espaço para o homem que, por isso mesmo estaria condenado a viver eternamente em condições primitivas (MARTINS, 1977).

Esse livro participou de grandes discussões no Brasil no final do século XIX, onde debates sobre questões como raça e adaptação do indivíduo ao meio, estavam em voga e intelectuais do porte de Silvio Romero preocuparam-se então em refutar as idéias de Buckle. Entretanto, até mesmo Romero não nega a ação do clima sobre o homem, apenas afirma que a natureza tropical é muito mais hostil do que pensa Buckle: o clima é variado, as terras não são todas férteis e o interior não é inteiramente coberto por florestas como o autor inglês imagina. Segundo Romero, a razão da barbárie do povo estaria ligada muito mais a ordem social prevalecente (MACHADO, 1995: 330).

Tomaz Pompeu, antecipando-se a Romero, concorda com Buckle, mais afirma que o Nordeste é diferente do resto do país. Nessa região o clima seco e a sobriedade da alimentação daí advinda criariam no homem condições para alcançar o progresso, gerando uma raça apta ao trabalho. A sobrevivência em um ambiente tão adverso traria a necessidade do homem cearense desenvolver suas forças mentais e físicas, o que acabaria gerando uma raça apta para qualquer trabalho. Seria, então, gerada através do meio físico uma sociedade fadada ao progresso mais do que em qualquer outra região do país. Analisando o censo demográfico de 1872 afirma:

Essa rápida progressão verificada pelo arrolamento oficial de 1872, a par de grandes e extensas crises climatéricas, que tem pesado sobre o 
solo cearense, roubando-lhe o melhor de sua seiva, deslocando povoações inteiras, arremessando-as ao litoral, e obrigando-as a êxodos tristíssimos, espécie de odisséia de lagrimas e dores, terminadas no nada do túmulo, esse desenvolvimento da população, a despeito de tudo denuncia na raça aptidões genésicas peculiares, e no meio físico, condições excepcionais de salubridade, dignas de estudo (...).

Clima quente e geralmente seco não exaure as forças musculares, nem debilita o homem (...) permitindo o uso de toda atividade, até idade avançada (BRASIL, 1890: 73-74) ${ }^{11}$.

Temos aqui uma coexistência entre as desgraças da seca e o desenvolvimento da população. A seca não impede seu crescimento devido às condições do meio físico e à raça que em função dele se desenvolveu. Na última frase temos uma estrutura muito semelhante a utilizada por Montesquieu, onde o clima teria influência sobre os “espíritos”. Aqui o clima quente criaria no homem um "espírito de trabalho”.

João Brígido dos Santos também publica um artigo em 1900 que está baseado em estatísticas que mostram o crescimento da população do Ceará a despeito das migrações para concluir que o clima é altamente favorável ao desenvolvimento do homem.

(...)o Ceará como o Rio Grande do Norte e outras regiões do antigo bispado de Pernambuco, era justamente a que melhores condições oferecia ao desenvolvimento da vida. Tudo estava disposto para que servisse de sementeiro da propagação do homem (SANTOS, 1900: 241).

Aqui mais uma vez o crescimento populacional é utilizado como fundamento para a adequação da região e seu meio físico ao povoamento. As condições físicas são apontadas por João Brígido como as determinantes do progresso populacional da região. Dessa forma, vemos que o elemento aglutinador desse grupo de artigos está no fato de associarem a dureza das condições climáticas ao sucesso do povoamento da região, e portanto, vendo o clima como um condicionante ao progresso.

\footnotetext{
11 As referências bibliográficas dos trabalhos publicados na Revista do Instituto do Ceará encontram-se em anexo à bibliografia geral do trabalho. Todos os grifos são nossos; A grafia foi atualizada.
} 


\section{Adjetivação trágica}

Paralelo a esse discurso, até o início do século XX é possível identificar um outro tipo de trabalho onde são realizadas exaustivas descrições de secas anteriores, refletindo uma tendência da Geografia e da Historiografia do século XIX de descrição de áreas e fatos. A tragédia inerente às secas é pintada com cores fortes, explorando ao extremo seu conteúdo trágico. São comuns as ligações entre as secas e adjetivos, como "terrível”, “arrasadora”, "horrorosa”, “mortífera”, ao lado da listagem de sua conseqüências. São trabalhos como os seguintes:

No ano de 1790 principiou, além de outras mais moderadas, uma seca tão terrível e rigorosa, que durou o espaço de 4 anos, porém no 1791 e 1792 mais excessiva, de tal sorte que derrubou, destruiu e matou quase todos os gados dos sertões desta comarca (...) (ALMEIDA, 1887: 85). Mar verdejante em época de chuvas, o sertão se transforma na estação seca em deserto de areia e pedra, de efeito tanto mais desolador quanto o aspecto de paus tortos (...) (KATZER, 1903: 295).

Não é desenvolvida nesses artigos uma estrutura de causa e efeito. Na verdade, tratam-se de trabalhos sem nenhuma preocupação explicativa, apenas estão concentrados em descrever o fenômeno das secas e seus estragos. Entretanto, esses autores ao descrevem a destruição causadas pelas secas impõe aos períodos de estiagem um caráter de tragédia, fornecendo assim, argumentos para aqueles que acusam a seca de ser responsável pelos problemas regionais.

O imaginário trágico que é forjado, ligado à idéia de inexorabilidade do meio é tão forte que torna fácil sua transformação para uma associação entre o atraso da região e seu meio físico. Esse discurso toma forma no início do século XX e o reforço de uma imagem trágica que o acompanha de tal maneira toma espaço, que exaure a visão anterior das possibilidades da dureza do clima como condicionante do progresso através dos desafios que são colocados à sociedade para sua superação. Esta perspectiva acaba sendo superada, no início deste século, por outra que ressalta a submissão e a impotência do Homem diante da inclemência das secas. 


\section{Seca e atraso}

No início do século XX é possível observar o crescimento de trabalhos com uma estrutura discursiva que apresenta uma associação entre o clima e o atraso da região. Atraso este, que aos poucos começa a ficar cada vez mais visível, principalmente se comparada ao crescimento da região sudeste do país.

As condições para esta discussão são dadas pelo adensamento populacional verificado no sertão nessa época (GUIMARÃES NETO, 1989: 44) e o baixo grau técnico dessas populações, transformando em calamidade para milhares de pessoas qualquer estiagem maior, que antes só era sentida por uma pequena população esparsamente distribuída pelo território.

A força que toma esse discurso está ligada também ao que Francisco de Oliveira chama de crescimento do "Nordeste algodoeiro-pecuária” que toma sua forma definitiva em finais do século XIX e princípios do século XX, através do fortalecimento da cultura do algodão no sertão, onde um primeiro impulso teria sido dado pela demanda das industrias européias, principalmente inglesa, e mais tarde pelo crescimento da indústria têxtil no Brasil (OLIVEIRA, 1977: 63).

O crescimento desse “Nordeste algodoeiro” no sertão, levou a uma perda relativa do controle político do "Nordeste açucareiro" na zona da mata e deu maior visibilidade ao sertão semi-árido, na medida em que este agora passa a desempenhar uma atividade econômica de vulto na região. É nesse momento que emerge a estrutura fundiária típica do latifúndio do sertão. É nesse momento também, que passa a existir uma elite econômica ,como aponta Oliveira,

Não é sem razão que tanto o controle político da nação começou a escapar das mãos da burguesia açucareira do "Velho Nordeste" quanto o controle político interno do "Velho" e do "Novo" Nordeste começou a passar as mãos da classe latifundiária que comandava o processo produtivo algodoeiro, reiterado pela sua subordinação aos interesses do capital comercial e financeiro inglês e norte-americano (OLIVEIRA, 1977: 35). 
É em virtude de tal fato que a imagem do Nordeste ligada à opulência dos "barões” do açúcar é gradativamente substituída pela imagem do latifúndio do sertão, dos “coronéis”, uma imagem rústica, pobre. É então, “nesse rastro que surge o Nordeste das secas” (OLIVEIRA, 1977).

Dessa forma, ao longo do século XX, é vulgarizado um discurso onde o meio físico, mais especificamente o clima semi-árido, sujeito a secas periódicas, é apontado como responsável pelo atraso da região. A relação causal de base dedutiva e determinista que se faz é: meio físico ruim / atraso. Essa relação algumas vezes aparece implícita e alinhada a outros fatores, mas outras vezes é delineada claramente. São trabalhos como o seguinte:

É conclusão que esta Capitania está sempre nascente, que a população não pode fazer progressos vantajosos, pelas emigrações continuas, ocorrências de secas, padecimento de moléstias dai provindas; o que tudo definha a espécie que devia aumentar-se rapidamente em relação da fecundidade e da propagação (...) (PAULET, 1898:13).

Nesse texto o autor é claro: a capitania não alcança o progresso devido a seca e seus resultados. A seca é vista como a responsável, a causa do atraso, tornando-se assim, um exemplo da estrutura relacional causa / efeito.

Pompeu Sobrinho em um artigo sobre a necessidade da irrigação, também coloca na natureza as causas do atraso da região:

É fácil verificar; as causas que determinam a lentidão do progresso nesta zona residem principalmente, senão exclusivamente, na penúria ou contingência das precipitações pluviométricas, impedindo o incremento das principais industrias locais - agricultura e criação de gado (POMPEU SOBRINHO, 1912: 215).

Pompeu Sobrinho, como já dissemos anteriormente, exerceu a presidência do DNCOS - Departamento Nacional de Obras Contra as Secas, e teve papel importante na decisão sobre suas ações. A grande influência de F. Ratzel em sua obra é evidenciada em partes de seu texto e no caráter das idéias aplicadas em sua presidência no DNOCS, como mostra F. Andrade: “As idéias do sistematizador das obras contra as secas eram pautadas em termos de Antropogeografia e entre linhas da Escola Determinista.” (ANDRADE, 1968: 28) 
Guilherme Studart, o Barão de Studart, que foi o responsável pela publicação da Revista do Instituto do Ceará por 35 anos, publica um artigo sobre a Geografia do Ceará encomendado pelo Governo Federal para as comemorações do centenário da independência em 1922. O autor é simples e direto:

Fora o Ceará uma região de chuvas regulares e bem distribuídas e no Brasil nenhum Estado lhe levaria vantagem; corta-lhe, porém, o vôo o para incomparáveis destinos a seca, que o persegue, devido a sua espécie disposição geográfica e as correntes aéreas que o cortam (STUDART, 1924: 29).

Para o autor, o único problema do Ceará é a falta de chuvas, a seca, cortandolhe o vôo para incomparáveis destinos e mantendo-o no atraso, independente do potencial que, como afirma, possui o estado.

Em artigo publicado no Jornal do Brasil e transcrito para a Revista do Instituto do Ceará em 1937, Júlio Paternostro é incisivo para com os problemas do Nordeste:

As gerações se sucedem sem ter iniciativas de trabalho; os filhos copiam os pais; estes copiaram os avós ... e qualquer tentativa no sentido de modificar-lhes os hábitos a natureza arrasa ainda no nascedouro. (...)

Quadro diferente, porém, nos apresenta o imigrante sertanejo, se transplantado para terras férteis, que tem água (PATERNOSTRO, 1937: 468).

Nesse texto, a natureza é implacável, impede qualquer tentativa de mudança na região. Os hábitos culturais da população são dados pela natureza, numa perfeita relação determinista clima/homem. Na última frase o autor também é claro: as causas do atraso não estariam ligadas ao nordestino, apesar de este "não merecer nenhum elogio a qualidade”, mas sim no meio-ambiente em que vive, já que se for transplantado para outras regiões apresentaria um quadro diferente ${ }^{12}$. O determinismo continua perpassando os trabalhos, como no de Guilherme de Souza Pinto:

${ }^{12}$ É interessante notar, como podemos encontrar uma estrutura semelhante em Monstequieu, porém com sentido inverso, como quando este autor, discutindo sobre a superioridade dos povos do norte, devido a seu clima, afirma: “(...) percebemos claramente que os povos do Norte, transportados para as regiões do Sul, aí não praticam tão belas ações como seus compatriotas (...).” (MONTESQUIEU, 1997: 278). 
Que é uma seca? É um fenômeno de natureza física com profunda repercussão nos meios econômico e social. São efeitos seus, o deslocamento das populações, a dizimação dos rebanhos, o aniquilamento da lavoura, com o seguinte cortejo: fome, morte, viuvez e orfandade; em uma palavra: a miséria (PINTO, 1938: 17).

Mais uma vez a condição de calamidade das secas é levantada, colocando-a como responsável pela miséria da população.

José Guimarães Duque também participa dessa perspectiva. Mesmo proposto a estudar as causas históricas do atraso no Nordeste, admite existirem causas naturais, como afirma na introdução de um artigo: "Pondo de lado as causas mesológicas do atraso do Nordeste, por serem demais conhecidas, (...)” (GUIMARÃES DUQUE, 1956: 61).

O autor admite que causas naturais existem para o atraso do Nordeste, apenas não as estuda "por serem demais conhecidas". Haveria causas históricas, as quais pretende estudar, mas a natureza também teria uma participação na falta do progresso no Nordeste.

Determinismo claro também é encontrado no trabalho de José Denizard de Alcantara:

Encontrando nas condições geofísicas do meio a razão fundamental dos seus problemas, especialmente os de ordem econômica, é obvia a interrogação dirigida a natureza dêste condicionamento fisiográfico, como ponto de partida primordial para o encontro das soluções requeridas pela problemática do Ceará (ALCANTARA, 1961: 27).

Podemos notar então, que o eixo principal de tratamento da temática seca em relação questão do progresso nesses artigos é a relação seca / atraso, relação essa que permanece até hoje, como mostramos no capítulo anterior, na veiculação de notícias sobre a seca na imprensa.

É evidente a relação entre seca e atraso no imaginário daqueles que no passado refletiam sobre as áreas de clima semi-árido no Brasil e a permanência dos traços essenciais dessa relação nos escritos do presente. São esses autores, responsáveis pela produção de um tipo de conhecimento presente na formação do senso comum, que é por sua vez, refletido nos jornais ainda hoje. 


\section{Considerações finais}

No discurso atual da seca nordestina é possível identificar um viés determinista que, em alguns é encontrado menos claro, mas que em outros é claramente delineado e desenvolvido. Nosso estudo se comprometeu a analisar a gênese desse determinismo e nos possibilitou alcançar algumas conclusões.

A partir da segunda metade do século XIX, com a preocupação da intelectualidade brasileira em traçar o perfil histórico, geográfico e cultural da nação brasileira, houve um considerável aumento desses estudos, nos quais o IHGB e os Institutos Regionais se destacam.

Aliado a isso, inicia-se a cultura do algodão no agreste e no semi-árido, atraindo novas atividades, como o comércio e seu beneficiamento, possibilitando forte adensamento populacional nessa área. Desse modo, as secas que antes afetavam áreas esparsamente povoadas, ganham maior visibilidade e passam a ter um caráter de tragédia, alcançando milhares de indivíduos sem os meios mínimos de sobrevivência durante as estiagens.

É nesse momento que a seca se transforma para uma quantidade grande de autores em uma questão. É nesse época também que o determinismo ambiental está sendo difundido e possibilita à Geografia incorporar alguns padrões exigidos pelas disciplinas científicas. Tal posicionamento reproduziu-se também nos trabalhos sobre a região semi-árida nordestina, apontando para a responsabilidade das correntes do determinismo ambiental, adotado nos diferentes escritos sobre a região, na gênese do discurso da seca.

O Discurso da seca nasce, dessa forma, já determinista. Entretanto, o estudo comprovou que existiram diferenças fundamentais dentro dos trabalhos analisados. No final do século XIX foi elaborado um discurso ligado ao Romantismo e à exaltação do solo pátrio. Nesta perspectiva, a rudeza do clima do Nordeste é visto como um determinante do progresso da região. Os autores responsáveis pela fundação desse discurso foram influenciados por uma matriz determinista que via nas adversidades climáticas um incentivo ao desenvolvimento das atividades intelectuais e tecnológicas no Homem. Para fundamentar sua posição, os autores nordestinos se baseavam principalmente nas elevadas taxas de crescimento da populacional. 
Um outro tipo de discurso identificado não faz ligação direta entre o clima e o progresso ou o atraso da região. Este é constituído, na verdade, de trabalhos descritivos que se preocupam em enumerar do ponto de vista histórico, a ocorrência freqüente de secas, relatando todos os seus estragos. São trabalhos ligados a uma tendência da Historiografia e Geografia do século XIX de descrição de fatos e áreas. Entretanto, nesses trabalhos a seca é sempre pintada com cores fortes, adjetivadas como tragédia e associada a vários problemas.

É também na virada do século XIX para o século XX, que a associação entre o clima e a miséria da região ganha contorno. As constantes secas já descritas por muitos como terríveis e arrasadoras passam a ser apontadas como a razão da miséria encontrada na região. Esse discurso baseado em um encadeamento simples de causas naturais e efeitos sociais ganha dimensão de verdade e é logo popularizado. Ao longo deste século esse discurso assume várias nuances, mas a base dedutiva causal é sempre a mesma: Seca / Atraso. Dessa forma, vemos como o discurso atual da seca nordestina, contaminado por visões deterministas tem sua origem em correntes filosóficas adotadas pela Geografia no final do século XIX.

\section{Referências}

ANDRADE, F. Alves de (1968): Três Humanistas no Instituto do Ceará. In: Revista do Instituto do Ceará, (82): 25-40.

BARDIN, Laurence (1994): Análise de Conteúdo. Lisboa: Edições 70.

BERDOULAY, Vincent (1988): Des Mots et des Lieux : la dynamique du discours géographique. Paris: Ed. Centre National de la Recherche Scientifique.

BOURDIEU, Pierre (1983): Sociologia. São Paulo: Ática.

— (1996): A economia das Trocas lingüísticas. São Paulo: EdUSP.

CARVALHO, Otamar de (1988): A economia política do Nordeste (seca, irrigação e desenvolvimento). Rio de Janeiro, Brasília: Campus, ABID.

CASTRO, Iná Elias de (1992): O Mito da Necessidade. Discurso e Prática do Regionalismo Nordestino. Rio de Janeiro: Bertrand Brasil.

—_ Da Seca como Tragédia à Seca como Recurso. Velhos e Novos Recursos, Velhos e Novos territórios (1994): In: Anuário do Instituto de Geociências. (17): 1-13.

- (1996): Seca versus seca. Novos interesses, novos territórios, novos discursos no Nordeste. In: CASTRO, I. E. et alli (org.), Brasil: Questões Atuais da Reogarnização do Território. Rio de Janeiro, Bertrand Brasil, p. 283-324. 
CLAVAL, Paul1 (1984): Les langages de la géographie et le rôle du discurs dans son évolution. In: Annales de Géographie, (518): 409-422. (1985): Causalité et Géographie. In: Espace Géographique, n. 2, p.109-115.

COELHO, Osvaldo (1985): Deputado diz que irrigação reverterá o estado de pobreza do Nordeste. ITEM, (20): 6-10.

ECO, Umberto (1993): Como se faz uma Tese. São Paulo: Perspectiva, 10a ed.

GELLNER, E. A. (1986): Determinismo. In: Dicionário de Ciências Sociais. Rio de Janeiro: Editora da FGV, p.340.

GOMES, Paulo Cesar da Costa (1987): As razões da Região. Rio de Janeiro: UFRJ, Tese de Mestrado.

_ (1996): Geografia e Modernidade. Rio de Janeiro: Bertrand Brasil.

GUIMARÃES, Manoel Luis Salgado (1988): Nação e Civilização nos Trópicos. O Instituto Histórico e Geográfico Brasileiros e o Projeto de uma História Nacional. In: Estudos Históricos. Rio de Janeiro, (1): 5-27.

GUIMARÃES NETO (1989): Leonardo. Introdução à formação econômica do Nordeste. Recife: Massangana, Fundação Joaquim Nabuco.

HAROCHE, C. \& PÊCHEUX, M. (1972) Manuel pour l'utilisation de la méthod de l'analyse automatique du discurs (AAD). T.A. Information, 13(1):13-55.

MACHADO, Lia Osório (1995). Origens do pensamento geográfico no Brasil: meio tropical, espaços vazios e a idéia de ordem (1870-1930). In: CASTRO, Iná E. et alli (org). Geografia: Conceitos e Temas. Rio de Janeiro: Bertrand Brasil,. p. 309-353.

MAIGUENEAU, Dominique (1993): Novas Tendências em Análise do discurso. Campinas, São Paulo: Ed. da Unicamp, Pontes, 2a ed.

MARTINS, Wilson (1977): História da Inteligência Brasileira. V.III (1855-1877). São Paulo: Cultrix, EdUSP.

MOLES, Abraham (1995): As ciências do Impreciso. Rio de Janeiro: Civilização Brasileira, p.371.

MONTESQUIEU [1748](1997). Do Espírito das Leis. São Paulo: Nova Cultural, (Col. Os Pensadores).

OLIVEIRA, Francisco (1977). Elegia para uma re(li)gião. SUDENE, Nordeste. Planejamento e conflitos de classes. Rio de Janeiro: Paz e Terra, Segunda Edição.

PÊCHEUX, Michel (1993): Análise Automática do Discurs In: GADET, F. \& HAK, T. (org.) Por uma análise automática do discurso. Uma introdução à obra de Michel Pêcheux. Campinas: Ed. Unicamp, p. 61-162.

PÊCHEUX, M. \& FUCHS, C. (1993): A Proprósito da Análise Automática do Discurso: atualização e perspectivas. In: GADET, F. \& HAK, T. (org.) Por uma análise automática do discurso. Uma introdução à obra de Michel Pêcheux. Campinas: Ed. Unicamp, p. 163-252. 
PINCHEMEL, P. (1957): Géographie et déterminisme. In: Bulletin de la société belge d'études gégraphiques, n.2, p.211-225.

POMIAN, Krystof (1990): Le déterminisme: histoire d'une problématique. POMIAN, K. (org.) La querelle du déterminisme. Paris: Galimard.

SYMANSKI, Richard (1976): The Manipulation of Ordinary Language. In: Annals of Association of American Geographers. (66):4, p.605-614.

\section{Anexo}

Artigos da Revista do Instituto do Ceará analisados (em ordem de publicação)

ALMEIDA, Manoel Esteves d'(1887): Registro de memória dos principais estabelecimentos, fatos e casos raros acontecidos nesta vila do Aracati. RIC (1): 83-86.

VASCOSELOS, Antonio. (1888): Município de Pereiro. RIC (2): 103-108 e 237-246.

BRASIL, Thomaz Pompeu de Souza (1890): População do Ceará. RIC (04): 253-272. (1890): População do Ceará em 1889, RIC (4): 253-272.

(1895): Juízo histórico do Senador Pompeu sobre fatos do Ceará. RIC, (9): 5-54.

FONSECA, Paulino N. (1895): O Coronel José Antônio injustamente acusado pelo presidente Coronel Antônio de Sales Nunes Belford. RIC (09): 291-329.

PAULET, Antonio (1898): Descrição geográfica abreviada da Capitania do Ceará. RIC (12): 5-33.

SANTOS, João B. (1903): Povoamento do Ceará. RIC (17): 291-298.

KATZER, F. (1903): Paisagens do Ceará., RIC (17): 291-298.

RODRIGUES, Barbosa (1907): A diminuição das águas no Brasil. RIC (21): 137-141.

BRASIL SOBRINHO, Thomaz Pompeu de S. (1912): Açude Quixeramobim. RIC (26): 215-279.

DIAS, A. (1913): Ceará. RIC (27): 228-242.

ROCHA, Augusto (1914): Notas Cronológicas de Canindé., RIC (28): 286-302.

FEIJÓ, J. (1914): Memória econômica sobre o gado lanigeiro. RIC (28): 367-397.

O’MEARA, P. (1918): A irrigação na vale do Jaguaribe. RIC (32): 91-119.

RIBEIRO, Raymundo F (1920): Breve noticia do vale do Jaguaribe. RIC (34): 331-350.

STUDART, Guilherme (1924): Geografia do Ceará. RIC (38): 3-124.

PATERNOSTRO, Julio (1937): O Nordeste. RIC (51): 464-469.

CASTRO, Jose L. (1937): O Nordeste. RIC (51): 469-485.

PINTO, G. (1938): Geografia econômica do Ceará. RIC (52): 17-34.

BRASIL SOBRINHO, T. P. (1940): Alguns aspectos da Geografia humana cearense. RIC (54): 153-192.

FACÓ, B. (1955): Fastos do Ceará. RIC, (69): 120-124.

DUQUE, J. G. (1956): As sociedades adiantadas e as retardadas. RIC (70): 61-73.

ALCANTARA, J. D. (1964): Roteiro econômico da Geografia do Ceará. RIC (75): 16-62.

MENEZES, Rui Simões (1983): O problema das secas. RIC (97): 171-173.

BOTELHO, C. L. (1991): O secular problema da seca . RIC (105): 95-108.

(1993):Uma visão geofísica da seca. RIC (107): 97-107. 